\title{
Co-infection with Hepatitis C Virus Increases Mortality in HIV-1 infected Patients through Increased Liver-Related Deaths Rather Than By Increasing Malignancy Related Deaths
}

\author{
Daniel O Griffin*, Michael J Metzger, Sheena Bharti, Arif Dharsee, Juan Carlos Rico and Joseph McGowan
}

Columbia University Medical Center, New York, USA

\begin{abstract}
Background: HIV-1-infected patients are living longer since the introduction of highly effective antiretroviral therapy (HAART). There is evidence that hepatitis $\mathrm{C}$ virus $(\mathrm{HCV}) / \mathrm{HIV}-1$ co-infection may result in an increased risk of death compared to patients infected only with HIV-1. Prior studies looking at this association have been limited by their enrollment of populations composed of mainly young MSM males. We investigated HCV/HIV-1-co-infection for an increased odds ratio for all cause mortality in a cohort representative of the current population in the US living with HIV-1-infection.
\end{abstract}

Methods: We performed an age-and-sex 1:1 matched case control study. We evaluated all deaths $(n=153)$ that occurred in a cohort of $\sim 2000$ patients from January 1, 2010-December 31, 2014 ( 10,000 patient life years) at a suburban clinic outside the NYC metropolitan area with a significant number of women and older individuals living with HIV-1-infection. We compared this cohort to an age and sex matched population selected from among 395 enrolled living HIV-1-infected controls.

Results: We observed that HCV/HIV-1-co-infection was associated with an increased odds ratio for all cause mortality of $1.83(95 \% \mathrm{Cl}, 0.99,3.43 ; \mathrm{P}=0.038)$ compared to HIV-1-mono-infected patients. Liver related deaths were the main cause of death with an odds ratio for liver related death with of $6.59(95 \% \mathrm{Cl}, 1.70,25.70 ; P=0.0005)$.

Conclusion: In an HIV-1-infected cohort, HCV/HIV-1-co-infection is associated with an increased odds ratio for all cause mortality driven by liver related mortality.

Keywords: HIV-1; HCV; Hepatitis C Virus; Mortality

\section{Introduction}

With the introduction of highly active antiretroviral therapy (HAART) HIV-1-infected patients are living longer [1]. Unfortunately HIV-1-infected individuals suffer significantly compared to their HIV-1-uninfected peers in terms of cancer diagnosis and mortality, hospital readmissions, and impact on health care utilization [2-6]. Comorbidities as well as chronic co-infections are becoming an increasing concern to patients and treating clinicians $[1,6,7]$. For one significant co-infection, Hepatitis C virus (HCV), newer, more effective and better-tolerated therapies are now available for patients on HAART [8]. Co-infection with HCV and HIV-1 may accelerate cirrhosis, increase hepatotoxicity, and increase mortality in HIV-1-infected patients on HAART [9-11]. Unfortunately previous studies looking at the impact of HCV co-infection in HIV-1-infected patients in the HAART era have been performed in predominantly young and male populations [12]. The HIV-1-infected population in the United States is characterized by a significant percentage of females, particularly women of color, as well as an aging population $[13,14]$.

Currently there are multiple available interferon sparing regimens for the treatment of HCV in HIV-1 patients [15-17]. These regimens have fewer side effects and are better tolerated by patients than prior interferon containing regimens. We examined, for the first time to our knowledge, the association of HCV with mortality in an HIV-1infected population containing the higher percentage of women and older patients that make up the current HIV-1-infected population.

\section{Materials/Patients and Methods}

We performed an age and sex 1:1 matched case control study. We analyzed de-identified patient records from the North Shore University
Hospital-LIJ Health System HIV clinic, a major suburban HIV clinic just outside the NY Metropolitan area, which follows 2,079 HIV-1infected patients. We evaluated all deaths $(n=153)$ that occurred in this cohort for 5 years from January 1, 2010-December 31, 2014 ( 10,000 patient life years) and classified the cause of death using the World Health Organization International Classification of Diseases diagnostic tool [18]. An age and sex matched sample of living clinic patients was selected during 2014-2015 to serve as the reference population $(n=153)$. A total of 395 patients were recruited randomly from the total clinic to serve as possible controls, and then age and sex matched controls were randomly selected to achieve 1:1 matching. Determination of patient age, sex, level of detectable virus in plasma, absolute CD4 count, Hepatitis $\mathrm{C}$ status, and antiretroviral therapy were obtained from review of the medical record. Last available recorded values were used. Age for living controls was as of September 9, 2015. Age for deceased was at time of death. Each categorization of cause of death was based on review of the death by a minimum of two clinicians active in the

*Corresponding author: Daniel O Griffin, MD PhD, Department of Biochemistry and Molecular Biophysics, Columbia University Medical Center, HHSC 1310c, 701 West 168th Street, New York, NY 10032 USA, Tel: 212-305-3794; Fax: 212-3055106; E-mail: dg2810@columbia.edu

Received February 18, 2016; Accepted March 15, 2016; Published March 25 2016

Citation: Griffin DO, Metzger MJ, Bharti S, Dharsee A, Rico JC, et al. (2016) Coinfection with Hepatitis C Virus Increases Mortality in HIV-1 infected Patients through Increased Liver-Related Deaths Rather Than By Increasing Malignancy Related Deaths. J AIDS Clin Res 7: 558. doi:10.4172/2155-6113.1000558

Copyright: ( 2016 Griffin DO, et al. This is an open-access article distributed unde the terms of the Creative Commons Attribution License, which permits unrestricted use, distribution, and reproduction in any medium, provided the original author and source are credited. 
Citation: Griffin DO, Metzger MJ, Bharti S, Dharsee A, Rico JC, et al. (2016) Co-infection with Hepatitis C Virus Increases Mortality in HIV-1 infected Patients through Increased Liver-Related Deaths Rather Than By Increasing Malignancy Related Deaths. J AIDS Clin Res 7: 558. doi:10.4172/2155-6113.1000558

Page 2 of 3

care of these patients. Statistical analysis was conducted using Stata 14 (StataCorp, College Station, Texas). Stratified analysis was used to compute the odds ratios (OR) for each variable alone, and the adjusted OR was calculated using Mantel-Haenszel adjustment. CD4 level and HIV viral load were considered as potential confounding variables. This study was conducted with approval from and in accordance with the standards of the North Shore-LIJ Health System Institutional Review Board.

\section{Results}

Over the 5-year period from January 1, 2010 through December 31, 2014 there were 153 deaths in the clinic population studied. The percentage of males among this group of deceased HIV-infected patients was $62.7 \%$ and females $37.3 \%$ with sex matched controls also being $62.7 \%$ males and $37.3 \%$ females $(n=153)$. The mean age in our deceased patients was 53 years old $(\mathrm{SD}=12)$ and 53 years old $(\mathrm{SD}=12)$ in our sample of age matched living HIV-infected controls. The prevalence of HCV infection in our deceased HIV-1-infected patients was $24.5 \%$ while the prevalence among our sample of age and sex matched living controls was $15.0 \%$. The percentage of patients with CD4 counts $<200$ cells $/ \mu \mathrm{L}$ was $48 \%$ in our deceased HIV-1-infected patients and $32 \%$ in our sample of age and sex matched living controls. The percentage of patients with a controlled HIV viral load $<500$ copies/mL was very similar between both groups with $71.7 \%$ of our deceased HIV-1infected patients having a viral load $<500$ copies $/ \mathrm{mL}$ and $73.2 \%$ of our sample of matched controls (Table 1).

We observed 153 deaths during the period from January 1, 2010-December 31, 2014 ( 10,000 patient life years). Deaths due to AIDS accounted for $17.0 \%$ of deaths $(n=26)$, cancer $32.7 \%(n=50)$, cardiovascular disease 2.6\% $(\mathrm{n}=4)$, infections-non AIDS related $7.2 \%$ $(n=11)$, liver $8.5 \%(n=13)$, renal $2.0 \%(n=3)$, respiratory $6.5 \%(n=10)$, violence, accident or suicidal death (VASD) $7.2 \%(n=11)$ and was unknown in $16.3 \%(n=25)$. While $35.1 \%$ of the deaths that occurred in the HCV negative patients were due to malignancies, only $24.3 \%$ of the deaths in the HCV infected patients were due to malignancies. There was also a lower percentage of deaths attributable to AIDS in the HCV infected patients $5.4 \%$ while $21 \%$ of the HCV negative patients had deaths attributable to AIDS. In contrast, while $5.3 \%$ of the deaths in the HCV negative population were liver related, $18.9 \%$ of the deaths in the HCV infected patients were liver related. There was also a lower percentage of deaths attributable to AIDS in the HCV infected patients 5.4\% while $21 \%$ of the HCV negative patients had deaths attributable to AIDS (Table 2).

When we analyzed the relationship between HCV infection and HIV we found that HCV co-infection in our cohort of HIV-1-infected individuals was associated with an increased odds ratio for all cause mortality of 1.83 (95\% Confidence Interval [CI], 0.99, 3.43; $P=0.038$ ).

\begin{tabular}{|l|c|c|}
\hline & Cases & Controls \\
\hline Characteristics & $\mathrm{n}(\%)$ & $\mathrm{n}(\%)$ \\
\hline Total & 153 & 153 \\
\hline Male/Female & $96(62.7) / 57(37.3)$ & $96(62.7) / 57(37.3)$ \\
\hline $\mathrm{CD} 4<200(\mathrm{cells} / \mu \mathrm{L})^{\mathrm{a}}$ & $73(48.0)$ & $49(32.0)$ \\
\hline $\mathrm{HIV} \mathrm{Viral} \mathrm{Load} \mathrm{<500} \mathrm{(copies/mL)}$ & $104(71.7)$ & $112(73.2)$ \\
\hline HCV+c* & $37(24.5)$ & $23(15.0)$ \\
\hline Age (years) mean +/- SD & $53+/-12$ & $53+/-12$ \\
\hline
\end{tabular}

${ }^{a}$ one case with missing data

${ }^{b *}$ eight cases with missing data

c**two cases with missing data

Hepatitis C Virus (HCV), Standard deviation (SD)

Table 1: Characteristics of cases and controls.
HIV viral load ( $<500$ copies $/ \mathrm{ml})$ and low CD4 count $(<200$ cells/ $\mu \mathrm{L})$ were analyzed as potential confounding variables. HIV viral load was not associated with mortality, but having a CD4 count below 200 cells/ $\mu \mathrm{L}$ was significantly associated with death (OR 1.96; 95\% CI 1.20, 3.21; $P=0.0043$ ). However, adjusting for CD4 level did not change the HCV association with mortality (Table 3 ). Additionally, the associations between HCV and mortality were similar within the low and high CD4 subjects $(1.85 ; 95 \%$ CI $0.85,4.08$; and 2.05 ; 95\% CI 0.68, 6.90; respectively), so there was no evidence of effect modification. The main driver of this increased mortality was liver related deaths with an odds ratio for liver related death with $\mathrm{HCV}$ co-infection of 6.59 (95\% CI, $1.70,25.70 ; P=0.0005$ ) (Table 4 ). This association was not affected by adjustment for CD4 level, sex, or age. When we excluded liver related deaths and evaluated all remaining classified deaths, there was no significant association with death; OR $1.2295 \% \mathrm{CI}, 0.59,2.46 ; P=0.56$. Due to the low numbers of cases in each of the other causes of death, further analysis of the OR with each subgroup was not possible.

Among the patients with liver related deaths, all patients who died from liver related causes $(n=13)$ were classified as cirrhotic with $85 \%$ of these patients $(n=11)$ dying from hepatic failure and $15 \%$ dying from upper gastrointestinal bleeding in the presence of advanced liver disease $(n=2)$. Both patients who died from an upper gastrointestinal bleed were co-infected with $\mathrm{HCV}$. There were three deaths due to hepatocellular carcinoma (classified as death due to malignancy rather than liver related) in this studied clinic population with two of these deaths occurring in HCV negative patients and one occurring in an HCV co-infected patient.

\begin{tabular}{|l|c|c|c|}
\hline Category & $\begin{array}{c}\text { All Patients } \\
\mathbf{n}(\mathbf{\%})\end{array}$ & $\begin{array}{c}\mathbf{H C V}^{\mathbf{a}} \mathbf{n} \\
\mathbf{( \% )}\end{array}$ & $\begin{array}{c}\mathbf{H C V}^{\mathbf{a}} \mathbf{n} \\
\mathbf{( \% )}\end{array}$ \\
\hline All mortality & 153 & 114 & 37 \\
\hline AIDS & $26(17.0)$ & $24(21.0)$ & $2(5.4)$ \\
\hline Cancer & $50(32.7)$ & $40(35.1)$ & $9(24.3)$ \\
\hline Cardiovascular disease & $4(2.6)$ & $4(3.5)$ & $0(0)$ \\
\hline Infection-nonAIDS & $11(7.2)$ & $7(6.1)$ & $4(10.8)$ \\
\hline Liver & $13(8.5)$ & $6(5.3)$ & $7(18.9)$ \\
\hline Renal & $3(2.0)$ & $2(1.8)$ & $1(2.7)$ \\
\hline Respiratory & $10(6.5)$ & $7(6.1)$ & $2(5.4)$ \\
\hline Violence, accident, or suicidal death & $11(7.2)$ & $9(7.9)$ & $2(5.4)$ \\
\hline Unknown & $25(16.3)$ & $15(13.2)$ & $10(27.0)$ \\
\hline
\end{tabular}

${ }^{a}$ Excluding cases with unknown HCV status $(n=2)$

Table 2: Observed mortality.

\begin{tabular}{|c|c|c|c|}
\hline & Cases $(n)^{a}$ & OR $(95 \% \mathrm{Cl})$ & $P$ value \\
\hline $\mathrm{HCV}$ & 151 & $1.83(0.99,3.43)$ & 0.038 \\
\hline CD4 $<200$ cells/ $\mu \mathrm{L}$ & 152 & $1.96(1.20,3.21)$ & 0.0043 \\
\hline HIV Viral Load $<500$ copies/mL & 145 & $0.93(0.54,1.59)$ & 0.78 \\
\hline Age $<50$ years & 153 & $0.97(0.59,1.60)$ & 0.90 \\
\hline HCV (adjusting for CD4 level) & 151 & $1.92(1.07,3.45)$ & 0.029 \\
\hline
\end{tabular}

a Excluding cases with unknown status. Controls have no missing data for these variables $(n=153)$

Table 3: Association with mortality.

\begin{tabular}{|l|c|c|c|}
\hline & $\mathrm{n}^{\text {a }}$ & OR $(\mathbf{9 5} \mathbf{c} \mathbf{C l})$ & P value \\
\hline All mortality & 151 & $1.83(0.99,3.43)$ & 0.038 \\
\hline Liver & 13 & $6.59(1.70,25.70)$ & 0.0005 \\
\hline All non-liver & 113 & $1.22(0.59,2.46)$ & 0.56 \\
\hline
\end{tabular}

a Excluding cases with unknown HCV status $(n=2)$

${ }^{b}$ Excluding cases with unknown cause of death $(n=25)$

Table 4: HCV Association with mortality. 
Citation: Griffin DO, Metzger MJ, Bharti S, Dharsee A, Rico JC, et al. (2016) Co-infection with Hepatitis C Virus Increases Mortality in HIV-1 infected Patients through Increased Liver-Related Deaths Rather Than By Increasing Malignancy Related Deaths. J AIDS Clin Res 7: 558. doi:10.4172/2155-6113.1000558

\section{Discussion}

With the number of competing priorities faced by the physician involved in the care of patients infected with HIV-1, it is important to allocate time and resources on areas with the greatest potential benefit. Our study shows that HCV co-infection is associated with a significant increased odd ratio for all cause mortality in the HIV-1-infected population. As expected, liver related deaths were the significant driver of this mortality risk. This suggests that HCV co-infection is mainly driving mortality through its role in liver pathogenesis, as one would have expected.

Chronic hepatitis $\mathrm{C}$ virus infection has been associated with allcause and liver-related mortality in HIV-infected patients in multiple setting and the mechanisms driving this are being elucidated [19-21]. While prior investigations demonstrating an association between HCV co-infection and mortality in the HIV-infected population have been on populations that have been largely young male dominated, our study included a significant proportion of females as well as older individuals and is more representative of the general population currently under consideration for HCV therapy [12]. In our study the mean age of patients was 53 years of age. Not only is the HIV-infected population in the United States aging, but patients over the age of 50 now make up a larger percentage of those newly diagnosed with HIV [22]. Our study also included a population in which women made up over $37 \%$ of the population. Women unfortunately are understudied and underrepresented in many studies on HIV in the United States despite the significant increase in the proportion of new HIV infection in the United States that are occurring in women [23]. Due to the high incidence of potential drug-drug interactions and modified monitoring, treatment of $\mathrm{HCV}$ in the HIV-1-infected population may require consultation with or referral to a physician skilled in the management of HAART. The significant increase in mortality seen in HCV co-infected patients in what is a more typical HIV-1-infected population should support the idea that despite potential complex drug-drug interactions, with increased monitoring requirement and modification of HAART when necessary, co-infected patients should have HCV therapy consideration made a priority.

\section{Author Contributions}

DOG designed the project, enrolled patients, collected data, performed data analysis, wrote the manuscript and constructed tables, MJM analyzed data, ran statistical evaluations, and was involved in writing the manuscript, SB was involved in the design of the project, enrollment of patients, and writing the manuscript, $A D$ was involved in the design of the project, data collection and writing the manuscript JCR participated in design of this project, data collection and writing the manuscript $\mathrm{JM}$ participated in design of this project, identification of patients for enrollment, and writing the manuscript.

\section{Acknowledgement}

Funding source-Donald and Barbara Zucker Family Foundation.

\section{References}

1. Harrison KM, Song $R$, Zhang $X$ (2010) Life expectancy after HIV diagnosis based on national HIV surveillance data from 25 states, United States. J Acquir Immune Defic Syndr 53: 124-130.

2. Berry SA, Fleishman JA, Moore RD, Gebo KA (2016) Thirty-day hospital readmissions for adults with and without HIV infection. HIV Med 17: 167-177.

3. Hellinger FJ (2015) Measuring the cost effectiveness of HIV prevention interventions in the US: pitfalls and problems. Appl Health Econ Health Policy 13: $129-133$

4. Hellinger FJ (2004) HIV patients in the HCUP database: a study of hospital utilization and costs. Inquiry 41: 95-105.

5. Griffin DO, Metzger M, Poeth K, Deng K, Dharsee A, et al. (2015) Malignancies,
Particularly B-Cell Lymphomas, Are a Frequent Cause of Mortality in Human Immunodeficiency Virus-1 Patients Despite Highly Active Antiretroviral Therapy. Open Forum Infect Dis 2: ofv147.

6. Rico JC, Schwartz RM, McGowan J, Griffin DO (2016) The Presence of a Malignant Comorbidity is a Significant Predictor of Increased 30-Day Hospital Readmission Rates in HIV-1-infected Individuals. Journal of AIDS and Clinical Research.

7. Armah KA, McGinnis K, Baker J, Gibert C, Butt AA, et al. (2012) HIV status, burden of comorbid disease, and biomarkers of inflammation, altered coagulation, and monocyte activation. Clin Infect Dis 55: 126-136.

8. Kaur K, Gandhi MA, Slish J (2015) Drug-Drug Interactions Among Hepatitis C Virus (HCV) and Human Immunodeficiency Virus (HIV) Medications. Infect Dis Ther 4: 159-172.

9. Hernando V, Perez-Cachafeiro S, Lewden C, Gonzalez J, Segura F, et al (2012) All-cause and liver-related mortality in HIV positive subjects compared to the general population: differences by HCV co-infection. J Hepatol 57: 743751

10. Greub G, Ledergerber B, Battegay M, Grob P, Perrin L, et al. (2000) Clinical progression, survival, and immune recovery during antiretroviral therapy in patients with HIV-1 and hepatitis C virus coinfection: the Swiss HIV Cohort Study. Lancet 356: 1800-1805.

11. Rotman Y, Liang TJ (2009) Coinfection with hepatitis C virus and human immunodeficiency virus: virological, immunological, and clinical outcomes. J Virol 83: 7366-7374.

12. Chen TY, Ding EL, Seage lii GR, Kim AY (2009) Meta-analysis: increased mortality associated with hepatitis $\mathrm{C}$ in HIV-infected persons is unrelated to HIV disease progression. Clin Infect Dis 49: 1605-1615.

13. Prejean J, Song R, Hernandez A, Ziebell R, Green T, et al. (2011) Estimated HIV incidence in the United States, 2006-2009. PLoS One 6: e17502.

14. CDC (2012) Estimated HIV incidence in the United States, 2007-2010. HIV Surveillance Supplemental Report.

15. Osinusi A, Townsend K, Kohli A, Nelson A, Seamon C, et al. (2015) Virologic response following combined ledipasvir and sofosbuvir administration in patients with HCV genotype 1 and HIV co-infection. JAMA 313: 1232-1239.

16. Sulkowski MS, Eron JJ, Wyles D, Trinh R, Lalezari J, et al. (2015) Ombitasvir paritaprevir co-dosed with ritonavir, dasabuvir, and ribavirin for hepatitis $\mathrm{C}$ in patients co-infected with HIV-1: a randomized trial. JAMA 313: 1223-1231.

17. Patel N1, Nasiri M, Koroglu A, Amin R, McGuey L, et al. (2015) Prevalence of drug-drug interactions upon addition of simeprevir- or sofosbuvir-containing treatment to medication profiles of patients with HIV and hepatitis $\mathrm{C}$ coinfection. AIDS Res Hum Retroviruses 31: 189-197.

18. World Health Organization (2007) International Statistical Classification of Diseases and Related health Problems, 10th revision. Geneva: World Health Organization.

19. Fuster D, Cheng DM, Quinn EK, Nunes D, Saitz R, et al. (2014) Chronic hepatitis $C$ virus infection is associated with all-cause and liver-related mortality in a cohort of HIV-infected patients with alcohol problems. Addiction 109: 62-70.

20. Nelson KE (2012) The impact of chronic hepatitis $C$ virus infection on mortality. $\mathrm{J}$ Infect Dis 206: 461-463.

21. Chen JY, Feeney ER, Chung RT (2014) HCV and HIV co-infection: mechanisms and management. Nat Rev Gastroenterol Hepatol 11: 362-371.

22. Brooks JT, Buchacz K, Gebo KA, Mermin J (2012) HIV infection and older Americans: the public health perspective. Am J Public Health 102: 1516-1526.

23. Weiss SM, Tobin JN, Antoni M, Ironson G, Ishii M, et al. (2011) Enhancing the health of women living with HIV: the SMART/EST Women's Project. Int J Womens Health 3: 63-77. 